Proceedings of the 90th JSCM Anniversary Conference

J. Jpn. Soc. Colour Mater., 91〔3], 85-88 (2018)

\title{
Organogel-in-Water Emulsions as Thermal-Energy Storage and Heat Transfer Fluids
}

\author{
Toshio SAKAI*, ${ }^{\dagger}$, Kosuke IIJIMA* and Kei Suzuki* \\ * Department of Materials Chemistry, Faculty of Engineering, Shinshu University, 4-17-1 Wakasato, Nagano 380-8553, Japan \\ $\uparrow$ Corresponding Author, E-mail: tsakai@shinshu-u.ac.jp
}

(Received November 28, 2017; Accepted January 28, 2018)

\begin{abstract}
We report here on the potential of organic phase-change material gel-in-water (OPCMG/W) emulsions as thermal-energy storage and heat transfer fluids. Gelation of OPCM droplets in OPCM/W emulsions enhanced the colloidal stability against temperature change in the range of -1 to $40^{\circ} \mathrm{C}$ and prevented the supercooling of OPCM droplets in the emulsions. Furthermore, the thermal properties of OPCMG particles in OPCMG/W emulsions were similar to those of OPCM alone.
\end{abstract}

Key-words: Organic phase-change material, Organogel-in-water emulsion, Thermal-energy storage, Heat transfer fluid, Supercooling

\section{Introduction}

Organic phase-change materials (OPCMs) such as paraffin have attracted attention as effective thermal-energy storage materials because of their high energy storage density afforded by the latent heat of OPCM during the phase change process, the tunability of phase-transition temperature by OPCM type and mixing of different OPCMs above $0^{\circ} \mathrm{C}$ and the reusability of OPCMs due to the chemical stability ${ }^{1-7)}$. The OPCM-in-water (OPCM/ W) emulsions are also attracting attention as thermalenergy storage and heat transfer fluids because of their thermal conductivity and thermal-energy transport due to the fluidity of the OPCM/W emulsions even below solidifyingtemperature of OPCM, the heat-transfer rates to the OPCM enhanced due to large specific surface area of OPCM and the tunability of temperature change of whole OPCM/W emulsions by combining latent heat of OPCM with sensible heat of water ${ }^{1-7)}$. In order to apply the OPCM/W emulsions as thermal-energy storage and heat transfer fluids to the practical thermal management system, higher colloidal stability of OPCM/W emulsions and control of supercooling of OPCM droplets in the emulsions are required ${ }^{7-21)}$. Then, we have investigated the effect of surfactant on the colloidal stability of OPCM/W emulsions and supercooling of OPCM droplets in the emulsions. We found that surfactants with longer hydrocarbon chain as a hydrophobic group are effective to enhance the colloidal stability of OPCM/W emulsions and prevent the supercooling of OPCM droplets in the emulsions ${ }^{22)}$.

In this work, we examine the potential of organic phasechange material gel-in-water (OPCMG/W) emulsions as thermal-energy storage and heat transfer fluids. We consider that the gelation of OPCM droplets in OPCM/W emulsions should enhance the colloidal stability of OPCM/W emulsions because the gelation of OPCM droplets in emulsions is expected to prevent the coalescence (fusion) of OPCM droplets even upon collision of OPCM droplets due to the higher viscoelasticity than liquid droplets. Also, the gelation of OPCM droplets in OPCM/W emulsions should prevent the supercooling of OPCM droplets in OPCM/W emulsions because 3D network formed in OPCM droplets should act as nuclei for solidification of OPCM droplets in emulsions.

\section{Experimental}

$\mathrm{OPCMG} / \mathrm{W}$ emulsions $(\mathrm{OPCM}$ content in water $=$ $30 \mathrm{vol} \%$ ) were prepared by mixing of OPCM containing an organic gelator ( $N$-Lauroyl- $L$-glutamic acid di- $n$-butylamide; LGBA, AJINOMOTO Co., Inc.) and ethanol $\left(\mathrm{C}_{2} \mathrm{H}_{5} \mathrm{OH}\right.$, Wako) with water using a rotor-stator homogenizer (CLEARMIX CLM-0.8S, M-Technique) at $60^{\circ} \mathrm{C}$ (see Fig. 1). Hexadecane $\left(\mathrm{C}_{16} \mathrm{H}_{34}, 99.2 \%\right.$, Tokyo Chemical Industry Co., Ltd) was used as an OPCM in this experiment. Colloidal stability and fluidity of hexadecane gel-in-water (HDG/W) emulsions were confirmed by monitoring the emulsion state before and after cooling (from $40^{\circ} \mathrm{C}$ to $-1^{\circ} \mathrm{C}$ ) and heating (from $-1{ }^{\circ} \mathrm{C}$ to $40^{\circ} \mathrm{C}$ ). Solidifying-temperature $\left(T_{\mathrm{s}}\right)$ and -period $\left(t_{\mathrm{s}}\right)$ of HDG particles in HDG/W emulsions were determined from the temperature stagnation caused by phase transition from liquid to solid and the period that temperature reached to $2^{\circ} \mathrm{C}$, respectively, during the cooling process of $\mathrm{HDG} / \mathrm{W}$ emulsions from $40^{\circ} \mathrm{C}$ to $-1^{\circ} \mathrm{C}$ (see upper panel of Fig. 2). The melting-temperature $\left(T_{\mathrm{m}}\right)$ and -period $\left(t_{\mathrm{m}}\right)$ of HDG particles in HDG/W emulsions were determined 


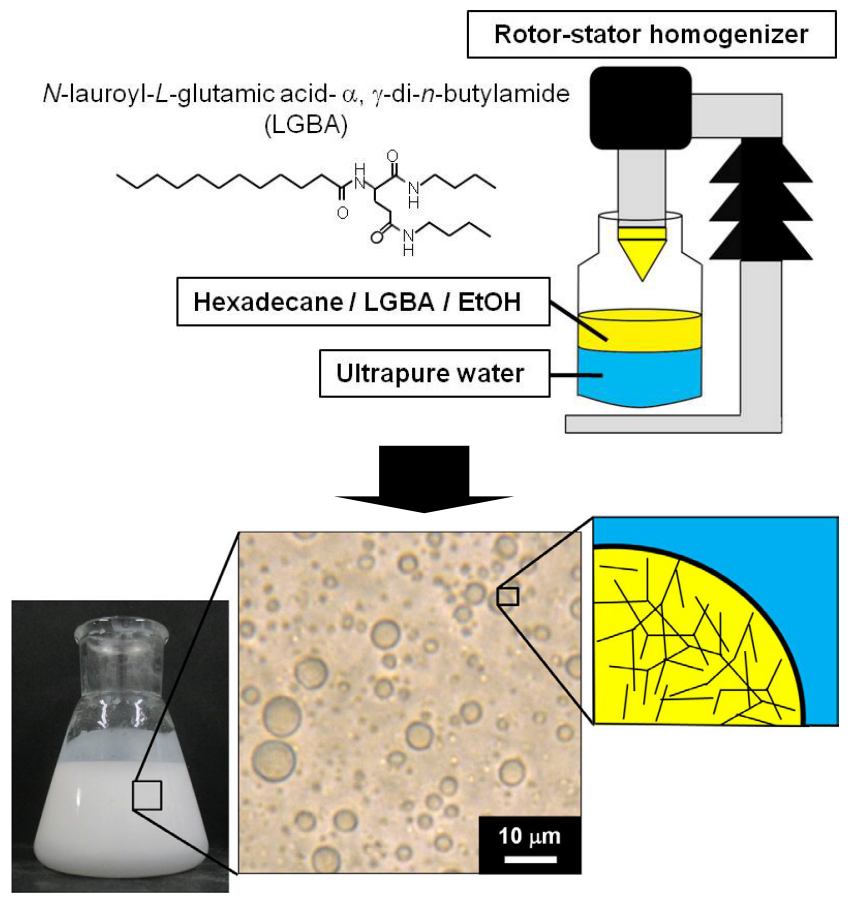

Fig. 1 (upper image) Schematic illustration of the preparation of OPCMG/W emulsion. (lower image) Prepared $\mathrm{OPCMG} / \mathrm{W}$ emulsion and optical micrograph.
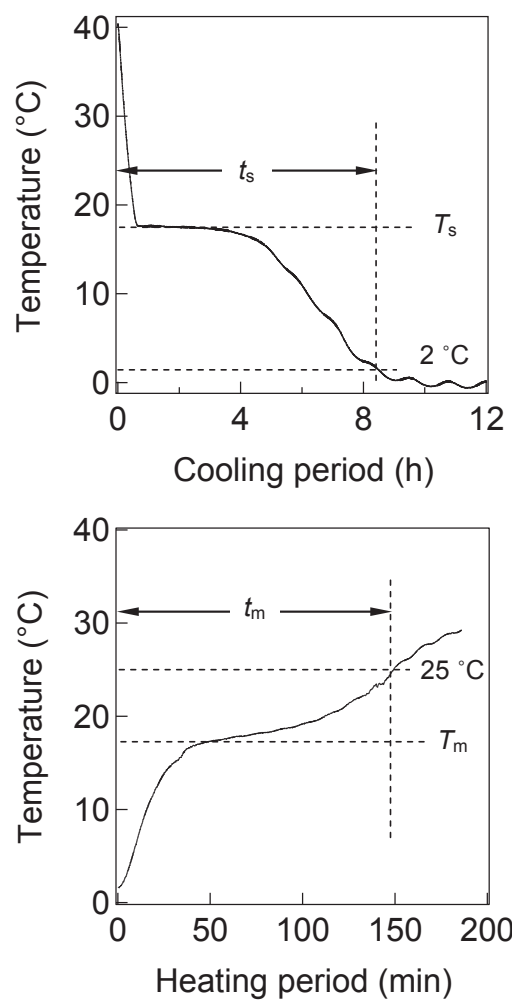

Fig. 2 (upper panel) Solidifying-temperature $\left(T_{s}\right)$ and -period $\left(t_{s}\right)$ of hexadecane (HD) determined by temperature stagnation caused by phase transition from liquid to solid and its period during the cooling process of $\mathrm{HD}$ from $40^{\circ} \mathrm{C}$ to $-1^{\circ} \mathrm{C}$. (lower panel) Melting-temperature $\left(T_{m}\right)$ and -period $\left(t_{m}\right)$ of hexadecane (HD) determined from temperature stagnation due to the phase transition from solid to liquid and its period during the heating process of $\mathrm{HD}$ from $-1{ }^{\circ} \mathrm{C}$ to $40^{\circ} \mathrm{C}$. from temperature stagnation due to the phase transition from solid to liquid and the period that temperature reached to $25^{\circ} \mathrm{C}$, respectively, during the heating process of $\mathrm{HDG} / \mathrm{W}$ emulsions from $-1{ }^{\circ} \mathrm{C}$ to $40^{\circ} \mathrm{C}$ (see bottom panel of Fig. 2).

\section{Results and discussion}

We first checked the colloidal stability of $\mathrm{HDG} / \mathrm{W}$ emulsions as a function of LGBA content in HD. In the case of no LGBA in HD ( $0 \mathrm{wt} \%$ in HD), HD and water did not mix with each other (see LGBA 0 wt $\%$ in HD in Fig. 3). On the other hand, homogeneous opaque dispersions were obtained by mixing of HD and water with the addition of LGBA to HD (see LGBA 1 and $3 \mathrm{wt} \%$ in HD in Fig. 3). It should be noted that the HD/W emulsions are colloidally stabilized by gelation of HD droplets with LGBA even in the absence of any stabilizing agents. With increase in the LGBA content in HD to $5 \mathrm{wt} \%$, HDG was separated from water (see LGBA $5 \mathrm{wt} \%$ in HD in Fig. 3). Furthermore, we found that the HDG/W emulsions prepared using a LGBA content of $3 \mathrm{wt} \%$ in $\mathrm{HD}$, in particular, remained dispersed even after cooling and heating processes of the HDG/W emulsion between $-1{ }^{\circ} \mathrm{C}$ and $40^{\circ} \mathrm{C}$ (see Fig. 3). This indicates the high colloidal stability of $\mathrm{HDG} / \mathrm{W}$ emulsions in the temperature range of $-1^{\circ} \mathrm{C}$ to $40^{\circ} \mathrm{C}$.

Having established the colloidal stability of $\mathrm{HDG} / \mathrm{W}$

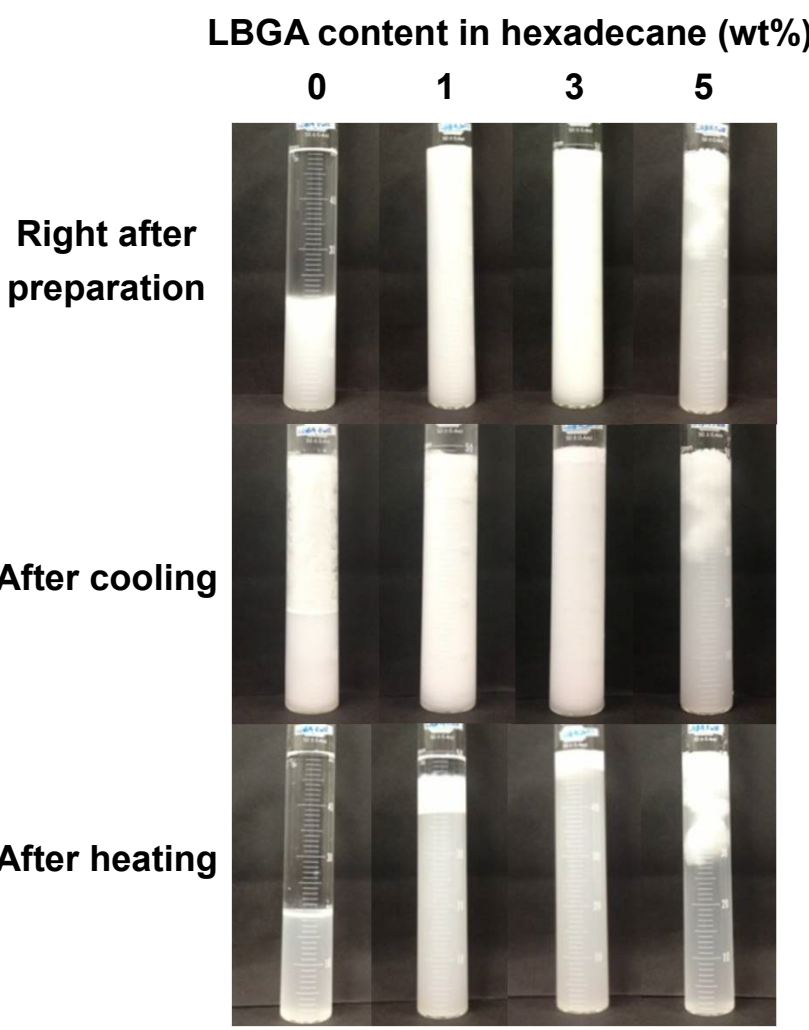

Fig. 3 Hexadecane-in-water (HD/W) emulsions prepared using a LGBA content of $0,1,3$ and $5 \mathrm{wt} \%$ in HD (upper images) immediately after preparation, (middle images) after cooling and (lower images) after heating. 

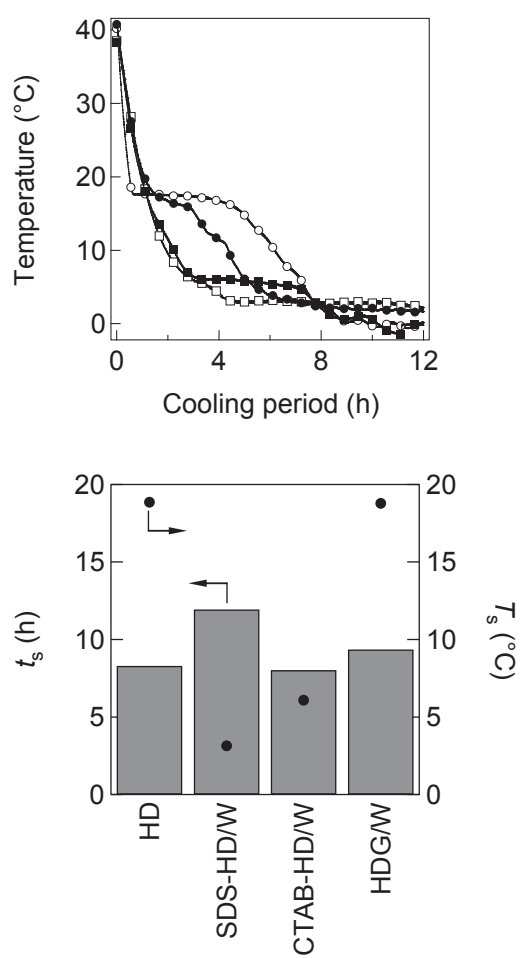

Fig. 4 (upper panel) Temperatures of $(\bigcirc)$ hexadecane (HD) $(60 \mathrm{~mL}),(\bigcirc) \mathrm{HDG} / \mathrm{W}$ emulsion prepared using a LGBA content of $3 \mathrm{wt} \%$ in $\mathrm{HD},(\square) \mathrm{HD} / \mathrm{W}$ emulsion stabilized by SDS and ( $\square$ ) HD/W emulsion stabilized by $\mathrm{CTAB}$ recorded during cooling process from $40^{\circ} \mathrm{C}$ to $-1{ }^{\circ} \mathrm{C}$. (lower panel) (O) Solidifying-temperature $\left(T_{s}\right)$ and (histogram) -period $\left(t_{s}\right)$ of HD alone (HD), HD droplets in HD/W emulsion stabilized by SDS (SDS$\mathrm{HD} / \mathrm{W}$ ), HD droplets in HD/W emulsion stabilized by CTAB (CTAB-HD/W) and HDG particles in HDG/W emulsion (HDG/W).

emulsions against temperature change in the range of $-1{ }^{\circ} \mathrm{C}$ to $40^{\circ} \mathrm{C}$, our interest turned to the supercooling of HD droplets in $\mathrm{HD} / \mathrm{W}$ emulsions. In general, the solidifyingtemperature $\left(T_{\mathrm{s}}\right)$ of paraffin droplets in paraffin/W emulsions is lower than that of paraffin alone, which implies the supercooling of paraffin droplets in paraffin $/ \mathrm{W}$ emulsions ${ }^{14-21}$. For example, the $T_{\mathrm{S}}$ of $\mathrm{HD}$ droplets in $\mathrm{HD} / \mathrm{W}$ emulsions stabilized by sodium dodecyl sulfate (SDS) and cetyltrimethylammonium bromide $(\mathrm{CTAB})$ are $\sim 3^{\circ} \mathrm{C}$ and $\sim 6^{\circ} \mathrm{C}$, respectively, which are confirmed from temperature stagnations of $\mathrm{HD} / \mathrm{W}$ emulsions during cooling process from $40^{\circ} \mathrm{C}$ to $-1^{\circ} \mathrm{C}$ (see Fig. 4). On the other hand, the $T_{\mathrm{s}}$ of HDG particles in HDG/W emulsions with a LBGA content of $3 \mathrm{wt} \%$ was $\sim 18^{\circ} \mathrm{C}$, which is also confirmed from a temperature stagnation of HDG/W emulsions during cooling process from $40^{\circ} \mathrm{C}$ to $-1{ }^{\circ} \mathrm{C}$ (see Fig. 4). The $T_{\mathrm{s}}$ of HDG particles in the HDG/W emulsion with a LBGA content of $3 \mathrm{wt} \%$ is consistent with that of HD alone (see Fig. 4). These findings indicate that the gelation of HD droplets in $\mathrm{HD} / \mathrm{W}$ emulsion prevents the supercooling of $\mathrm{HD}$ droplets in the emulsion. This is most likely due to the 3D network of LGBA formed in HD droplets acting as nuclei for
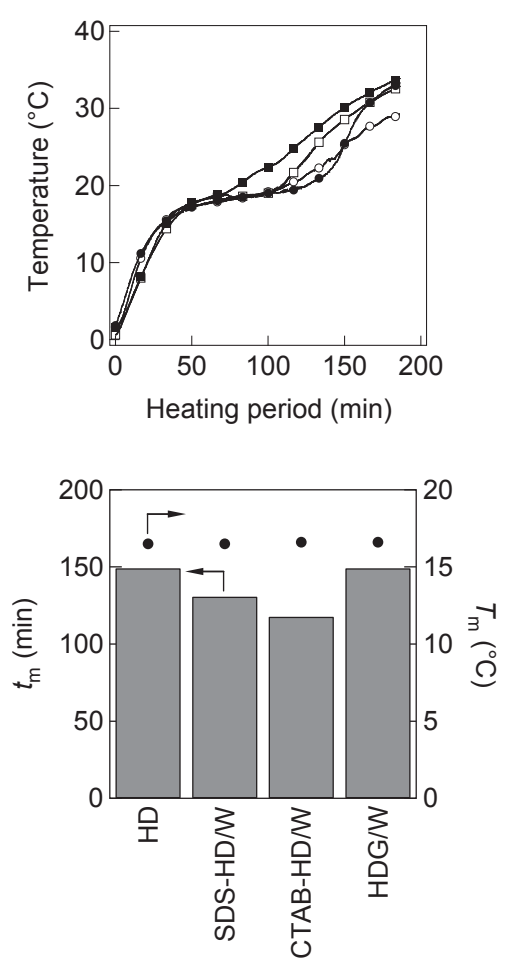

Fig. 5 (upper panel) Temperatures of $(\bigcirc)$ hexadecane (HD) $(60 \mathrm{~mL}),(\mathbf{O}) \mathrm{HDG} / \mathrm{W}$ emulsion prepared using a LGBA content of $3 \mathrm{wt} \%$ in $\mathrm{HD},(\square) \mathrm{HD} / \mathrm{W}$ emulsion stabilized by SDS and $(\square) \mathrm{HD} / \mathrm{W}$ emulsion stabilized by $\mathrm{CTAB}$ recorded during heating process from $-1^{\circ} \mathrm{C}$ to $40^{\circ} \mathrm{C}$. (lower panel) $(\bigcirc)$ Melting-temperature $\left(T_{m}\right)$ and (histogram) -period $\left(t_{m}\right)$ of HD alone (HD), HD droplets in $\mathrm{HD} / \mathrm{W}$ emulsion stabilized by SDS (SDS-HD/W), HD droplets in HD/W emulsion stabilized by CTAB (CTAB-HD/W) and HDG particles in HDG/W emulsion (HDG/W).

solidification of HD droplets in the emulsion. It should be noted here that the solidifying-period $\left(t_{\mathrm{s}}\right)$ of HDG particles in the HDG/W emulsion is shorter than that of HD droplets in HD/W emulsions stabilized by SDS (see Fig. 4).

Finally, we confirmed the latent heat of HDG particles in $\mathrm{HDG} / \mathrm{W}$ emulsion with a LBGA content of $3 \mathrm{wt} \%$ in HD. The melting-temperature $\left(T_{\mathrm{m}}\right)$ and -period $\left(t_{\mathrm{m}}\right)$ of HDG particles in the HDG/W emulsion was the same as those of HD alone (see Fig. 5). This implies that thermal properties of HD remain unchanged even after gelation of HD droplets in $\mathrm{HD} / \mathrm{W}$ emulsions. Note here that $t_{\mathrm{m}}$ of HDG particles in the HDG/W emulsion was longer than those of HD droplets in $\mathrm{HD} / \mathrm{W}$ emulsions stabilized by SDS and CTAB while the $T_{\mathrm{m}}$ of HDG particles in the HDG/W emulsion was the same as those of HD droplets in HD/W emulsions stabilized by SDS and CTAB. The shorter solidifying-period $\left(t_{\mathrm{s}}\right)$ and longer melting-period $\left(t_{\mathrm{m}}\right)$ lead to the advantageous in energy conversion efficiency ( $=$ ratio of output energy/input energy). The energy conversion efficiency of HDG/W emulsions, which is given by the ratio of melting-period to solidifyingperiod $\left(t_{\mathrm{m}} / t_{\mathrm{s}}\right)$, becomes higher than $\mathrm{HD} / \mathrm{W}$ emulsions stabilized by SDS and CTAB (see Fig. 6). 


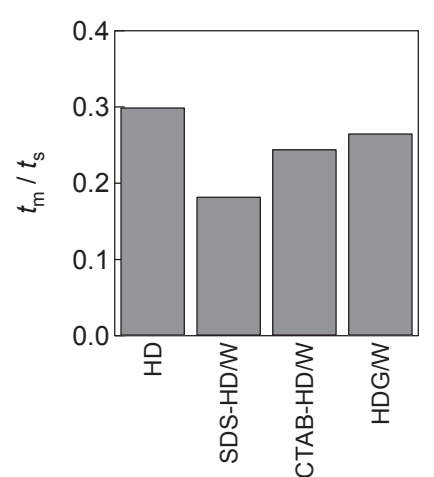

Fig. 6 Ratios of melting-period $\left(t_{m}\right)$ to solidifying-period $\left(t_{s}\right)$ of HD alone (HD), HD droplets in HD/W emulsion stabilized by SDS (SDS-HD/W), HD droplets in HD/W emulsion stabilized by CTAB (CTAB-HD/W) and HDG particles in HDG/W emulsion (HDG/W).

\section{Conclusions}

HDG/W emulsions with a HD content of 30 vol\% were prepared by gelation of HD droplets in HD/W emulsions while HD and water did not mix with each other in the absence of any stabilizing agents. Furthermore, the colloidal stability of $\mathrm{HD} / \mathrm{W}$ emulsion against temperature change in the range of -1 to $40^{\circ} \mathrm{C}$ was enhanced by the gelation of HD droplets in HD/W emulsion. The supercooling of HD droplets in HD/W emulsions was prevented by gelation of HD droplets in HD/W emulsions. These findings prove the potential of OPCMG/W emulsions as thermal-energy storage materials and heat transfer fluids.

\section{References}

1) H. Inaba: Int. J. Therm. Sci., 39 (9-11), 991 (2000).

2) S. Jegadheeswaran, S. D. Pohekar: Renew. Sustain. Energy Rev., 13 (9), 2225 (2009).

3) S. Jegadheeswaran, S. D. Pohekar, T. Kousksou: Renew. Sustain. Energy Rev., 14 (9), 2580 (2010).

4) H. Inaba, S. Morita: J. Heat Transfer, 117 (2), 440 (1995).

5) H. Inaba, S. I. Morita: Int. J. Heat Mass Transfer, 39 (9), 1797 (1996).

6) T. Kousksou, A. Jamil, S. Gibout, Y. Zeraouli: J. Therm. Anal. Calorimetry, 96 (3), 841 (2009).

7) T. El Rhafiki, T. Kousksou, A. Jamil, S. Jegadheeswaran, S. D. Pohekar, Y. Zeraouli: Sol. Energy Mater. Sol. Cells, 95 (9), 2588 (2011).

8) H. Inaba, S.-i. Morita, S. Nozu: Jpn. Soc. Mech. Eng., 59 (565), 282 (1993).

9) D. J. McClements, S. R. Dungan, J. B. German, C. Simoneau, J. E. Kinsella: J. Food Sci., 58 (5), 1148 (1993).

10) N. Kaneko, T. Horie, S. Ueno, J. Yano, T. Katsuragi, K. Sato: J. Cryst. Growth, 197 (1-2), 263 (1999).

11) D. Rousseau: Food Res. Int., 33, 3 (2000).

12) R. Montenegro, M. Antonietti, Y. Mastai, K. Landfester: J. Phys. Chem. B, 107 (21), 5088 (2003)

13) K. Golemanov, S. Tcholakova, N. D. Denkov, T. Gurkov: Langmuir, 22 (8), 3560 (2006)

14) L. W. Phipps: Trans. Faraday Soc., 60, 1873 (1964).

15) J. N. Coupland: Curr. Opin. Colloid Interface Sci., 7 (5-6), 445 (2002).

16) L. Huang, M. Petermann, C. Doetsch: Energy, 34 (9), 1145 (2009).

17) M. J. Oliver, P. D. Calvert: J. Cryst. Growth, 30 (3), 343 (1975).

18) H. Kraack, E. B. Sirota, M. Deutsch: J. Chem. Phys., 112 (15), 6873 (2000).

19) E. B. Sirota, A. B. Herhold: Science, 283 (5401), 529 (1999).

20) W. Skoda, M. Van den Tempel: J. Colloid Sci., 18 (6), 568 (1963).

21) D. H. Rasmussen, M. R. Appleby, G. L. Leedom, S. V. Babu, R. J. Naumann: J. Cryst. Growth, 64 (2), 229 (1983).

22) T. Sakai, Y. Nakagawa, K. Iijima: Colloids Surf. A, 529, 394 (2017). 